\title{
The feasibility and safety of using sublaminar polyester bands in hybrid spinal constructs in children and transitional adults for neuromuscular scoliosis
}

\author{
*Sohum K. Desai, MD, Christina Sayama, MD, Daniel Vener, Alison Brayton, RN, \\ Valentina Briceño, RN, Thomas G. Luerssen, MD, and Andrew Jea, MD \\ Neuro-Spine Program, Division of Pediatric Neurosurgery, Texas Children's Hospital, Department of Neurosurgery, Baylor \\ College of Medicine, Houston, Texas
}

\begin{abstract}
OBJECT The authors have previously reported on their early experience with sublaminar polyester bands in spine surgery. In this paper, the authors describe the use of sublaminar polyester bands in long-segment posterior instrumented spinal fusions from the upper thoracic spine to the ilium in 21 children and transitional adults with progressive neuromuscular scoliosis. Transitional adults were patients older than 18 years of age with a spinal disorder of pediatric onset, such as spina bifida. This dedicated study represents the first reported use of polyester bands in spine surgery for neuromuscular scoliosis in this patient population in the US.
\end{abstract}

METHODS The authors retrospectively reviewed the demographics and procedural data of patients who underwent posterior instrumented fusion using sublaminar polyester bands for neuromuscular scoliosis.

RESULTS Twenty-one pediatric and adult transitional patients, ranging in age from 10 to 20 years (mean 14 years), underwent posterior instrumented fusion for progressive neuromuscular scoliosis. The average coronal Cobb angle measured $66^{\circ}$ before surgery (range $37^{\circ}-125^{\circ}$ ). Immediately after surgery, the mean coronal Cobb angle was $40^{\circ}$ (range $13^{\circ}-85^{\circ}$ ). At last follow-up, the average coronal Cobb angle was maintained at $42^{\circ}$ (range $5^{\circ}-112^{\circ}$ ). Regarding sagittal parameters, thoracic kyphosis was restored by $8 \%$, and lumbar lordosis improved by $20 \%$ after surgery. Mean followup duration was 17 months (range 2-54 months). One patient with an aborted procedure due to loss of intraoperative evoked potentials was excluded from the analysis of radiographic outcomes. Mean surgical time was 7 hours 43 minutes (range 3 hours 59 minutes to 10 hours 23 minutes). All patients received either a 12- or 24-mg dose of recombinant human bone morphogenetic protein-2. Average estimated blood loss was $976 \mathrm{ml}$ (range 300-2700 ml). Complications directly related to the use of sublaminar instrumentation included transient proprioceptive deficit (1 patient) and prolonged paraparesis (1 patient). Other complications noted in this series included disengagement of the rod from an iliac screw (1 patient), proximal junctional kyphosis (1 patient), noninfected wound drainage (2 patients), and perioperative death (1 patient). The lessons learned from these complications are discussed.

CONCLUSIONS Pedicle screws, laminar/pedicle/transverse process hooks, and sublaminar metal wires have been incorporated into posterior spinal constructs and widely reported and used in the thoracic and lumbar spines and sacrum with varying success. This report demonstrates the satisfactory radiological outcomes of hybrid posterior spinal constructs in pediatric and adult neuromuscular scoliosis that include sublaminar polyester bands that promise the technical ease of passing sublaminar instrumentation with the immediate biomechanical rigidity of pedicle screws and hooks. However, the high neurological complication rate associated with this technique (2/21, or $10 \%)$ tempers the acceptable radiographic outcomes.

http://thejns.org/doi/abs/10.3171/2014.9.PEDS1468

KEY WORDS pediatric spine; transitional adults; spine surgery; spinal instrumentation; sublaminar polyester bands

\footnotetext{
ABBREVIATIONS AP = anteroposterior; $\mathrm{CP}=$ cerebral palsy; $\mathrm{HRQoL}=$ health-related quality of life; MCS = Mental Component Score; MEP = motor evoked potential; ODI = Oswestry Disability Index; PCS = Physical Component Score; PedsQL = Pediatric Quality of Life; rhBMP-2 = recombinant human bone morphogenetic protein-2; SF-36 = 36-Item Short Form Health Survey; SRS = Scoliosis Research Society; SSEP = somatosensory evoked potential.

SUBMITTED February 17, 2014. ACCEPTED September 8, 2014.

INCLUDE WHEN CITING Published online January 2, 2015; DOI: 10.3171/2014.9.PEDS1468.

DISCLOSURE The authors report no conflict of interest concerning the materials or methods used in this study or the findings specified in this paper.

* Drs. Desai and Sayama contributed equally to this work.
} 
$\mathrm{L}$ AMINAR hooks, pedicle screws, and sublaminar wires made of stainless steel, titanium alloys, or cobalt chromium alloys have been used to varying degrees of success as anchors, or fixation points, in the instrumented fusion of the pediatric spine. There are strengths and weakness to each of these modalities of fixation to bone. The ideal device should meld the technical ease of sublaminar wires, the adaptability of hooks, and the biomechanical stability of screws.

Apical sublaminar wires and pedicle screw instrumentation offer similar outcomes in terms of degree of deformity correction. ${ }^{7}$ When compared with sublaminar wire/hook constructs and hybrid wire/hook/screw constructs, all-pedicle-screw constructs did not confer a significant advantage in terms of deformity correction. ${ }^{27}$ Furthermore, in weak or skeletally immature bone, laminar hooks have been shown to possess a better pullout profile than pedicle screws. ${ }^{8}$ In the pediatric population, not all patients will be anatomically suited for hook or pedicle screw implantation. Therefore, no 1 type of construct has been demonstrated to be superior over others.

In this paper we report on the treatment of 21 pediatric and transitional adult patients with neuromuscular scoliosis who underwent posterior instrumented fusion with hybrid hook-screw-sublaminar polyester band constructs. Transitional adults were patients older than 18 years of age with a spinal disorder of pediatric onset, such as spina bifida. The flexibility and gentleness of polyester and decreased contact stresses at the bone-band interface due to increased surface area for bone contact makes this type of instrumentation ideal for the anatomically smaller and skeletally immature pediatric spine, or transitional adults with anomalous bone anatomy. However, as with other forms of sublaminar spinal instrumentation, the neurological complication rate is high. ${ }^{20}$ To our knowledge, this study represents the first devoted report of the use of polyester bands in spine surgery for neuromuscular scoliosis in the US.

\section{Methods}

\section{Patient Population}

We retrospectively reviewed the records of 21 consecutive patients who underwent posterior instrumented spinal fusions by the Neuro-Spine Service at The Texas Children's Hospital between January 1, 2008, and December 31, 2013 (Tables 1 and 2). Preoperative 36-inch radiographs of the spine, CT scans, and MR images were obtained in all patients. Immediate postoperative 36-inch radiographs of the spine in the upright position were obtained in all patients. Postoperative full-spine radiographs and $\mathrm{CT}$ scans at 3 months were obtained in follow-up to document fusion. Thereafter, clinical and radiographic follow-up with full-spine radiographs were performed at 6- to 12-month intervals. Health-related quality of life (HRQoL) outcomes were collected using the Pediatric Quality of Life Inventory (PedsQL) measurement model (4 patients), Scoliosis Research Society (SRS)-22 patient questionnaire (11 patients), the Oswestry Disability Index (ODI; 6 patients), and the 36-Item Short Form Health Survey (SF-36; 4 patients; Table 3). One patient (Case 21) whose surgery was aborted because of unexpected intraoperative loss of evoked potentials was excluded from further analysis beyond patient demographics, operative data, and radiographic outcomes; her case is highlighted in the following Case Illustration.

\section{Implant Characteristics}

The Universal Clamp (Zimmer, Inc.) is FDA-approved for use in spinal trauma, deformity correction (including neuromuscular scoliosis), and degenerative spinal disease. The system incorporates a sublaminar polyester band made from woven Dacron and has a malleable metal portion at its tip that aids in the sublaminar placement. The polyester band measures $6 \mathrm{~mm}$ wide $\times 1 \mathrm{~mm}$ thick (Fig. 1). The wider dimension of the polyester band when compared with sublaminar wires helps to distribute the corrective forces over a larger surface area of bone. ${ }^{16}$ The sublaminar clamp mechanism possesses a high strength to failure $(1400 \pm 180 \mathrm{~N})$ during axial loading. In addition, the torque to failure during rotational grip testing is also robust $(4.4 \pm 0.4 \mathrm{Nm})$.

Passing the polyester band under the lamina does require a learning curve. Those already proficient in the use of sublaminar wires will acquire proficiency more readily. The malleable metal end of the polyester band is shaped into a gentle curve for passage around the lamina. The band is always passed in a caudal to rostral direction. The tip of the band is gripped with hemostats or forceps, and the rest of the passage follows a push-pull technique, being careful to keep tension so that a loop of band does not compress the thecal sac. After all of the sublaminar bands have been passed, each of the clamps is closed over the rods. The locking screw is then loosely engaged into the clamp, and reduction/deformity correction can be performed with the tensioner. Once the optimal correction has been obtained the locking screw is fully engaged and the excess bands may be cut. Although the final tension is primarily evaluated by the surgeon, the tensioner does have a mark indicating when the maximum recommended tension of $500 \mathrm{~N}$ has been reached.

\section{Surgical Technique}

All patients were positioned prone after intubation. Neurophysiological monitoring was used for all cases; motor evoked potential (MEP) and somatosensory evoked potential (SSEP) baseline parameters for the lower extremities were obtained prior to skin incision. The posterior thoracic and lumbar spine, sacrum, and posterosuperior iliac spine were exposed in the usual manner. Entry points for iliac screws were prepared. The ligamentum flavum was resected above and below laminae where hooks and sublaminar polyester bands were to be placed. Iliac bolts and laminar hooks (Legacy, Medtronic Sofamor Danek) were then implanted in the usual way, ${ }^{10}$ followed with the placement of the polyester bands as detailed above. MEPs and SSEPs were obtained after each passage of the sublaminar band.

Osteotomies as required by the particular case and spinal deformity were performed prior to securing the 5.5-mm-diameter titanium rods to the laminar hooks and 
TABLE 1. Preoperative and operative data in 21 patients with neuromuscular spinal deformity who underwent scoliosis surgery using hybrid constructs with sublaminar polyester bands

\begin{tabular}{|c|c|c|c|c|c|c|c|c|c|c|}
\hline \multirow{2}{*}{$\begin{array}{l}\text { Case } \\
\text { No. }\end{array}$} & \multirow{2}{*}{$\begin{array}{l}\text { Age (yrs), } \\
\text { Sex }\end{array}$} & \multirow{2}{*}{$\begin{array}{c}\text { Associated } \\
\text { Comorbidities }\end{array}$} & \multirow{2}{*}{$\begin{array}{c}\text { Primary Spinal } \\
\text { Deformity }\end{array}$} & \multicolumn{2}{|c|}{ Preop Cobb Angles $\left(^{\circ}\right)$} & \multirow{2}{*}{$\begin{array}{c}\text { Spinal } \\
\text { Construct }\end{array}$} & \multirow{2}{*}{$\begin{array}{c}\text { rhBMP-2 } \\
\text { Dosage (mg) }\end{array}$} & \multirow{2}{*}{$\begin{array}{l}\text { Sublaminar } \\
\text { Bands Used }\end{array}$} & \multirow{2}{*}{$\mathrm{EBL}(\mathrm{ml})$} & \multirow{2}{*}{$\begin{array}{l}\text { Op Time } \\
\text { (hrs:min) }\end{array}$} \\
\hline & & & & Coronal & Sagittal & & & & & \\
\hline 1 & $14, \mathrm{~F}$ & SB & Kyphoscoliosis & 101 & $89(\mathrm{~T}), 60(\mathrm{~L})$ & T2-ilium & 12 & 18 & 1100 & $10: 00$ \\
\hline 2 & $13, \mathrm{~F}$ & $\mathrm{CP}$ & Scoliosis & 81 & $35(\mathrm{~T}), 58(\mathrm{~L})$ & T4-ilium & 12 & 18 & 2000 & 8:00 \\
\hline 3 & $14, \mathrm{M}$ & $\mathrm{CP}$ & Kyphoscoliosis & 52 & $41(\mathrm{~T}), 34(\mathrm{~L})$ & T4-ilium & 24 & 24 & 300 & $6: 00$ \\
\hline 4 & $14, \mathrm{M}$ & $\mathrm{CP}$ & Kyphoscoliosis & 86 & $73(\mathrm{~T}), 10(\mathrm{~L})$ & T2-ilium & 24 & 23 & 350 & $7: 47$ \\
\hline 5 & $15, \mathrm{M}$ & $\mathrm{CP}$ & Scoliosis & 85 & $8(\mathrm{~T}), 30$ (L) & T4-ilium & 12 & 16 & 2500 & $8: 07$ \\
\hline 6 & $11, \mathrm{M}$ & $\mathrm{CP}$ & Kyphoscoliosis & 70 & $10(\mathrm{~T}),-99(\mathrm{~L})$ & T5-ilium & 24 & 15 & 500 & $4: 34$ \\
\hline 7 & $11, \mathrm{~F}$ & SB & Scoliosis & 45 & $25(\mathrm{~T}), 44(\mathrm{~L})$ & T2-ilium & 24 & 14 & 450 & $8: 36$ \\
\hline 8 & $13, \mathrm{M}$ & $\mathrm{CP}$ & Kyphoscoliosis & 53 & $53(\mathrm{~T}), 24(\mathrm{~L})$ & T1-ilium & 12 & 26 & 450 & $6: 53$ \\
\hline 9 & $16, \mathrm{M}$ & Other & Scoliosis & 37 & $13(\mathrm{~T}), 36(\mathrm{~L})$ & T4-ilium & 24 & 24 & 2400 & $8: 25$ \\
\hline 10 & $15, M$ & $\begin{array}{l}\text { Diastemato- } \\
\text { myelia }\end{array}$ & Scoliosis & 53 & $55(\mathrm{~T}), 63(\mathrm{~L})$ & T4-L4 & 24 & 14 & 700 & $7: 19$ \\
\hline 11 & $20, M$ & SB & Kyphoscoliosis & 100 & $46(\mathrm{~T}), 62(\mathrm{~L})$ & T2-ilium & 24 & 12 & 500 & $10: 00$ \\
\hline 12 & $13, \mathrm{M}$ & $\mathrm{CP}$ & Kyphoscoliosis & 42 & $48(\mathrm{~T}), 13(\mathrm{~L})$ & T2-ilium & 24 & 24 & 700 & $6: 26$ \\
\hline 13 & $10, F$ & SB & Kyphoscoliosis & 50 & $48(\mathrm{~T}), 47(\mathrm{~L})$ & T4-ilium & 12 & 20 & 500 & $8: 24$ \\
\hline 14 & $14, F$ & SB & Kyphoscoliosis & 62 & $32(\mathrm{~T}), 60(\mathrm{~L})$ & T2-ilium & 12 & 16 & 600 & $8: 56$ \\
\hline 15 & $12, \mathrm{~F}$ & $\mathrm{CP}$ & Scoliosis & 51 & $47(\mathrm{~L}), 24(\mathrm{~T})$ & T4-ilium & 12 & 20 & 1300 & $6: 00$ \\
\hline 16 & $15, \mathrm{M}$ & SB & Kyphoscoliosis & 46 & $98(\mathrm{~T}), 49(\mathrm{~L})$ & T2-ilium & 24 & 26 & 500 & $6: 41$ \\
\hline 17 & $10, F$ & $\mathrm{CP}$ & Kyphoscoliosis & 54 & $67(\mathrm{~T}), 17(\mathrm{~L})$ & T2-ilium & 24 & 24 & 800 & $7: 26$ \\
\hline 18 & $17, \mathrm{~F}$ & $\mathrm{CP}$ & Scoliosis & 42 & $38(\mathrm{~T}), 43(\mathrm{~L})$ & T2-ilium & 24 & 14 & 1200 & $3: 59$ \\
\hline 19 & $13, F$ & $\begin{array}{l}\text { Spinal muscle } \\
\text { atrophy }\end{array}$ & Scoliosis & 90 & $30(\mathrm{~L}), 5(\mathrm{~T})$ & T2-ilium & 24 & 22 & 2700 & $9: 14$ \\
\hline 20 & $14, \mathrm{~F}$ & $\mathrm{CP}$ & Scoliosis & 125 & $24(\mathrm{~T}), 16(\mathrm{~L})$ & T1-ilium & 24 & 24 & 600 & $10: 23$ \\
\hline 21 & $14, F$ & $\mathrm{CP}$ & Scoliosis & 57 & $22(\mathrm{~T}), 66(\mathrm{~L})$ & T3-ilium & 24 & 16 & 350 & $9: 12$ \\
\hline Mean & $14, F$ & NA & NA & 66 & $43(\mathrm{~T}), 41(\mathrm{~L})$ & NA & NA & 20 & 976 & $7: 43$ \\
\hline
\end{tabular}

$(\mathrm{L})=$ lumbar; $N A=$ not applicable; $S B=$ spina bifida (myelomeningocele); $(\mathrm{T})$ = thoracic.

pedicle screws. The polyester band was attached to the rod with a titanium alloy clamp and locking screw. Reduction maneuvers were performed by sequential tightening of each band-clamp implant against the lamina and rod with a tensioner.

Arthrodesis was performed with local autograft, morselized cancellous allograft, and recombinant human bone morphogenetic protein-2 (rhBMP-2) in all cases (Infuse, Medtronic Sofamor Danek) after proper decortication, except in Case 21. No bone harvest from other sites was performed.

\section{Characteristics of Pseudarthrosis}

The criteria used to detect pseudarthroses were 1) loss of fixation, such as implant breakage, dislodgement of rods or hooks, or halo around a pedicle screw (halo around an iliac screw is an expected finding from preservation and motion of the sacroiliac joint); 2) significant progression of deformity with or without pain; 3) subsequent disc space collapse observed from the first postoperative visit to the most recent visit where pseudarthrosis was determined; and 4) lucency across the fusion mass on postoperative CT.

The effect of patient age at surgery, sex, and comorbidities at surgery were evaluated. Coronal Cobb angle, thoracic kyphosis from T-5 to T-12, and lumbar lordosis from L-1 to L-5 were measured radiographically using upright 36-inch scoliosis radiographs before surgery, immediately after surgery, and at last follow-up, respectively. The percentage of curve correction was calculated based on coronal Cobb angles.

\section{Statistical Analysis}

Clinical, operative, and radiographic parameters were collected. Frequency distributions and summary statistics were calculated for these data.

\section{Illustrative Case History and Examination}

Case 21 was a 14-year-old girl with a history of cerebral palsy (CP), spastic triplegia (right arm and both legs), seizure disorder, and severe developmental delay. She was evaluated in the neurosurgery spine clinic for progressive neuromuscular scoliosis. Standing scoliosis radiographs showed an S-shaped deformity with a right-sided thoracolumbar curve measuring $38^{\circ}$ and a left-sided lumbar curve measuring $57^{\circ}$ (Fig. 2). On further questioning of the parents, there were no complaints of back pain, leg pain, worsening leg weakness, or bladder/bowel dysfunction.

On examination, our patient would not cooperate with a formal neurological examination. She did have increased tone in the legs, but she did not appear to have any weak- 
TABLE 2. Patient postoperative data in 21 patients with neuromuscular spinal deformity who underwent scoliosis surgery using hybrid constructs with sublaminar polyester bands

\begin{tabular}{|c|c|c|c|c|c|c|c|c|c|}
\hline \multirow{2}{*}{$\begin{array}{l}\text { Case } \\
\text { No. }\end{array}$} & \multicolumn{2}{|c|}{$\begin{array}{c}\text { Postop Cobb } \\
\text { Angles }\left(^{\circ}\right)\end{array}$} & \multicolumn{2}{|c|}{$\begin{array}{l}\text { Cobb Angle at Last } \\
\text { Follow-Up }\left(^{\circ}\right)\end{array}$} & \multirow{2}{*}{$\begin{array}{l}\text { Follow-Up } \\
\text { (mos) }\end{array}$} & \multicolumn{2}{|c|}{$\begin{array}{l}\% \text { Correction In } \\
\text { Sagittal Plane }\end{array}$} & \multirow{2}{*}{$\begin{array}{l}\% \text { Correction } \\
\text { in Coronal } \\
\text { Plane }\end{array}$} & \multirow[b]{2}{*}{ Comments } \\
\hline & Coronal & Sagittal & Coronal & Sagittal & & Lumbar & Thoracic & & \\
\hline 1 & 62 & $68(\mathrm{~T}), 50(\mathrm{~L})$ & 62 & $68(\mathrm{~T}), 49(\mathrm{~L})$ & 54 & 2 & 0 & 64 & $\begin{array}{l}\text { Proprioception defect in It lower ex- } \\
\text { tremity }\end{array}$ \\
\hline 2 & 22 & $42(\mathrm{~T}), 47(\mathrm{~L})$ & 41 & 47 (T), 29 (L) & 49 & 38 & 10 & 49 & \\
\hline 3 & 14 & $13(\mathrm{~T}), 44(\mathrm{~L})$ & 22 & $14(\mathrm{~T}), 48(\mathrm{~L})$ & 38 & 8 & 7 & 57 & \\
\hline 4 & 73 & $114(\mathrm{~T}), 35(\mathrm{~L})$ & 59 & $61(\mathrm{~T}), 14(\mathrm{~L})$ & 29 & 60 & 46 & 31 & $\begin{array}{l}\text { Proximal junctional kyphosis w/in } 3 \\
\text { mos postop requiring extension } \\
\text { of fusion }\end{array}$ \\
\hline 5 & 85 & $11(\mathrm{~T}), 23(\mathrm{~L})$ & 92 & $9(\mathrm{~T}), 31(\mathrm{~L})$ & 25 & 25 & -18 & -8 & $\begin{array}{l}\text { Rehospitalized 1-mo postop for } \\
\text { pleural effusion }\end{array}$ \\
\hline 6 & 73 & $4(\mathrm{~T}),-46(\mathrm{~L})$ & 61 & $16(\mathrm{~T}),-52(\mathrm{~L})$ & 2 & 12 & 75 & 13 & $\begin{array}{l}\text { Deceased } 2 \text { mos postop due to respi- } \\
\text { ratory failure at an outside facility }\end{array}$ \\
\hline 7 & 23 & $22(\mathrm{~T}), 44(\mathrm{~L})$ & 30 & $25(\mathrm{~T}), 45(\mathrm{~L})$ & 24 & 2 & 12 & 49 & \\
\hline 8 & 22 & $36(\mathrm{~T}), 46(\mathrm{~L})$ & 23 & $33(\mathrm{~T}), 36(\mathrm{~L})$ & 21 & 22 & -8 & 57 & \\
\hline 9 & 19 & $18(\mathrm{~T}), 26(\mathrm{~L})$ & 21 & $6(\mathrm{~T}), 28(\mathrm{~L})$ & 17 & 8 & -67 & 43 & \\
\hline 10 & 37 & $36(\mathrm{~T}), 51(\mathrm{~L})$ & 35 & $34(\mathrm{~T}), 45(\mathrm{~L})$ & 14 & 12 & 6 & 34 & \\
\hline 11 & 51 & $34(\mathrm{~T}), 57(\mathrm{~L})$ & 45 & $36(\mathrm{~T}), 24(\mathrm{~L})$ & 12 & 58 & 6 & 55 & Disengagement of rod from iliac bolt \\
\hline 12 & 25 & $36(\mathrm{~T}), 7(\mathrm{~L})$ & 36 & 20 (T), 16 (L) & 10 & 56 & -45 & 14 & Noninfected seroma drainage \\
\hline 13 & 16 & $32(\mathrm{~T}), 55(\mathrm{~L})$ & 22 & $42(\mathrm{~T}), 54(\mathrm{~L})$ & 9 & 2 & 24 & 56 & Noninfected seroma drainage \\
\hline 14 & 30 & $38(\mathrm{~T}), 51(\mathrm{~L})$ & 33 & $22(\mathrm{~T}), 57(\mathrm{~L})$ & 9 & 11 & -73 & 47 & \\
\hline 15 & 25 & $41(\mathrm{~L}), 30(\mathrm{~T})$ & 24 & $37(\mathrm{~L}), 26(\mathrm{~T})$ & 9 & 10 & 31 & 53 & \\
\hline 16 & 18 & $37(\mathrm{~T}), 43(\mathrm{~L})$ & 23 & $34(\mathrm{~T}), 43(\mathrm{~L})$ & 8 & 0 & 9 & 50 & \\
\hline 17 & 24 & $26(\mathrm{~T}), 37(\mathrm{~L})$ & 26 & $31(\mathrm{~T}), 41(\mathrm{~L})$ & 8 & 10 & 17 & 52 & \\
\hline 18 & 13 & $13(\mathrm{~T}), 30(\mathrm{~L})$ & 5 & $26(\mathrm{~T}), 38(\mathrm{~L})$ & 8 & 22 & 38 & 88 & \\
\hline 19 & 81 & $31(\mathrm{~L}), 7(\mathrm{~T})$ & 73 & $45(\mathrm{~L}), 14(\mathrm{~T})$ & 8 & 32 & 50 & 19 & \\
\hline 20 & 83 & $22(\mathrm{~T}), 55(\mathrm{~L})$ & 112 & $32(\mathrm{~T}), 55(\mathrm{~L})$ & 6 & 0 & 31 & 10 & \\
\hline $21^{*}$ & NA & NA & NA & NA & 5 & NA & NA & NA & Incomplete SCl; surgery aborted \\
\hline Mean & 40 & $32(\mathrm{~T}), 39(\mathrm{~L})$ & 42 & $32(\mathrm{~T}), 37(\mathrm{~L})$ & 17 & 20 & 8 & 42 & \\
\hline
\end{tabular}

$\mathrm{SCl}=$ spinal cord injury.

* Case 21 was excluded from postoperative Cobb angle calculations as her surgery was aborted.

ness in her legs. She was ambulating independently. There were no upper motor neuron signs, such as clonus or upgoing toes on Babinski response, except hyperreflexia throughout. The patient had an obvious right rib hump deformity. Given the progressive nature and magnitude of her scoliosis, surgical stabilization was offered to the parents. The goal of surgery was to prevent progression of her neuromuscular scoliosis and achieve a moderate degree of correction of her spinal deformity.

\section{Operation}

The patient was taken to the operating room for a posterior instrumented fusion from T-3 to the ilium. Needle electrodes were placed in the upper and lower extremities to monitor SSEPs and MEPs. Baseline potentials in the lower extremities showed good stable waveforms. The patient was turned prone, and a standard exposure of the posterior elements of the spine from T-3 to the iliac crest was performed.

Bilateral iliac screws were placed under fluoroscopic guidance. ${ }^{8}$ Laminar hooks were planned at T-3 and T-4.
Sublaminar polyester bands were passed from L-3 to L-5 and then T-5 to T-10. During passage of the sublaminar band at T-10, we perceived a "jerk" of the patient. Subsequently, there was a complete loss of SSEPs and MEPs in the lower extremities. Further handling of the spine and spinal cord were halted, steroids were administered, the mean arterial pressures were raised, and the dosage of intravenous anesthetic medication was reduced; after 1 hour of intraoperative manipulation of various parameters to improve spinal cord perfusion, there was no improvement in her electrophysiological signals. We decided to abort the rest of the surgery at this point.

We left the sublaminar polyester bands in place. We did not believe they would offer a compressive force on the spinal cord. In the postoperative period, we did obtain both an MR image and a CT myelogram to document that there was no spinal cord compression.

\section{Postoperative Course}

The patient was kept in the intensive care unit for 2 days of administration of steroids and maintenance of mean ar- 
TABLE 3. Health-related quality of life outcomes

\begin{tabular}{|c|c|c|c|c|c|}
\hline \multirow[b]{2}{*}{ Case No. } & \multicolumn{5}{|c|}{ HRQoL Outcomes } \\
\hline & PedsQL & SRS- $22 r+^{*}$ & ODI & SF-36 PCS & SF-36 MCS \\
\hline \multicolumn{6}{|l|}{1} \\
\hline \multicolumn{6}{|l|}{2} \\
\hline \multicolumn{6}{|l|}{3} \\
\hline 4 & & & $35 \%$ & 34.2 & 52.7 \\
\hline \multicolumn{6}{|l|}{5} \\
\hline \multicolumn{6}{|l|}{6} \\
\hline \multicolumn{6}{|l|}{7} \\
\hline 8 & 15 & & & & \\
\hline 9 & & 5.42 & & & \\
\hline 10 & & 4.14 & & & \\
\hline 11 & & 3.63 & $18 \%$ & 55 & 31.5 \\
\hline 12 & 35.53 & & & & \\
\hline 13 & & 4.14 & & & \\
\hline 14 & & 3.82 & $36 \%$ & 44 & 40.2 \\
\hline 15 & & 4.61 & & & \\
\hline 16 & & 4.5 & & & \\
\hline 17 & & 4.59 & & 57.1 & 62.5 \\
\hline \multicolumn{6}{|l|}{18} \\
\hline 19 & 77.17 & 4.32 & $28 \%$ & & \\
\hline 20 & & 3.73 & $53 \%$ & & \\
\hline 21 & 85.87 & 4.54 & $15 \%$ & & \\
\hline Mean & 53.39 & 4.31 & $31 \%$ & 47.6 & 46.7 \\
\hline
\end{tabular}

* The SRS-22r+ is the version of the SRS-22 survey that was used.

terial pressure between 80 and $100 \mathrm{~mm} \mathrm{Hg}$. Sensation in the lower extremities returned at 2 days after surgery. Motor function was limited to a triple flexion response.

The patient was eventually transferred to our inpatient rehabilitation unit where she continues to recover slowly. At 3 weeks after surgery, she now has antigravity strength in the proximal lower extremities. She is able to stand and bear weight with minimal assistance. There is no evidence of neurogenic bladder, as she maintains the sensation to void without any radiographic evidence of postvoid residual. The patient does suffer from constipation, however.

We are optimistic that this patient will continue to recover and regain an independent ambulatory status. Once she reaches a plateau in her neurological recovery, however, we will recommend completion of her spinal construct to stabilize her scoliosis.
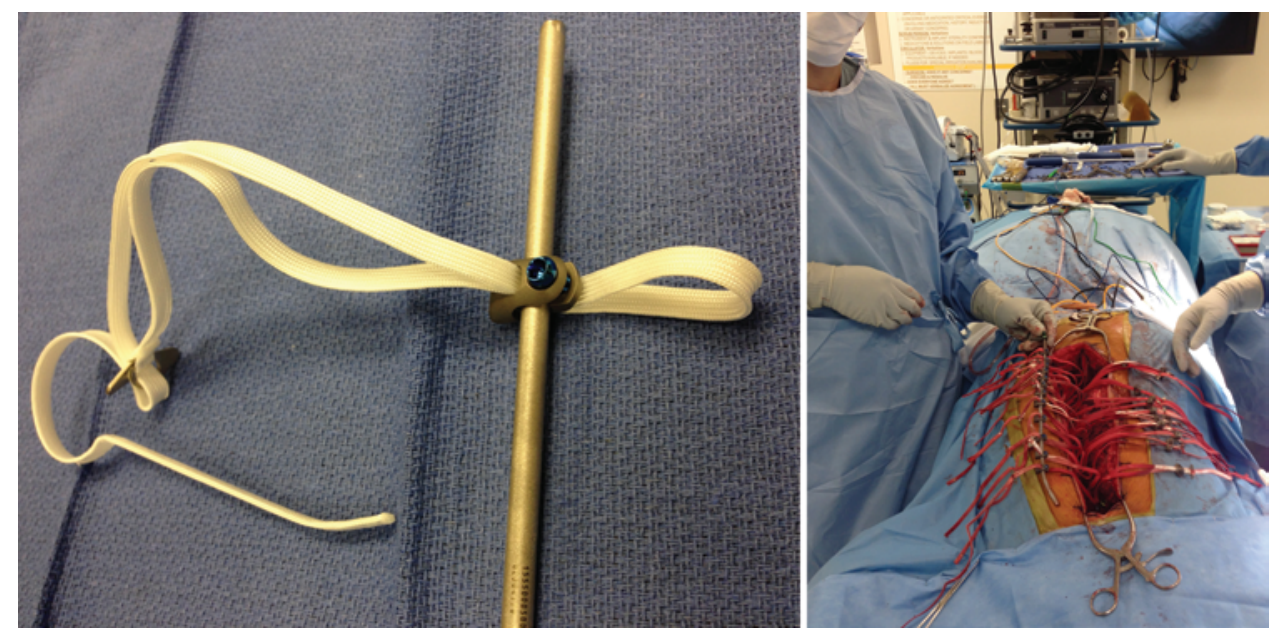

FIG. 1. Left: Close-up photograph shows the Universal Clamp with the sublaminar polyester band, used as a fixation point between the spine and a 5.5-mm-diameter rod. Right: Intraoperative photograph displays the Universal Clamps in place and attached to a rod on the right side. Figure is available in color online only. 


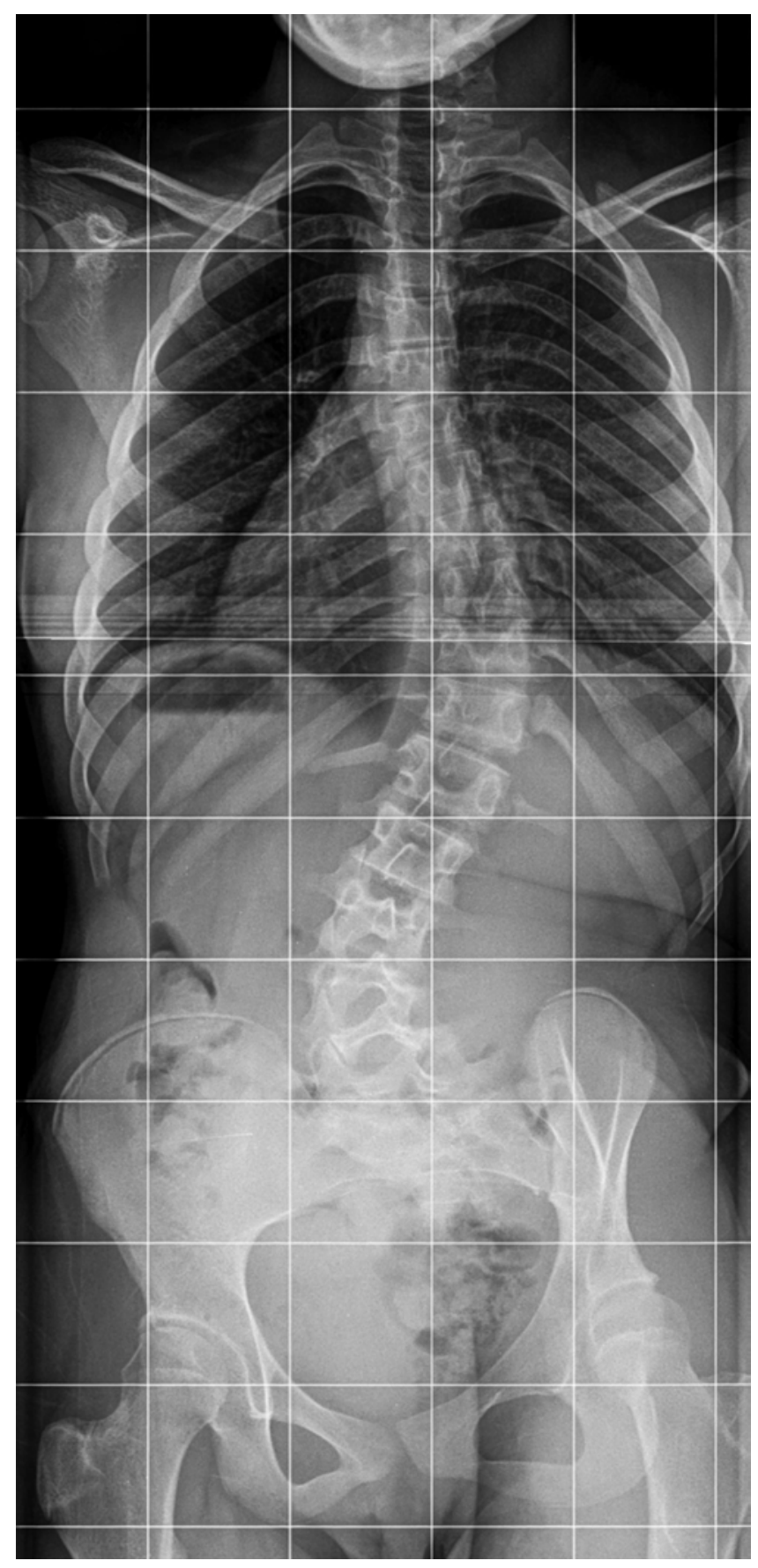

FIG. 2. Case 21. Standing AP 36-inch scoliosis radiograph showing an S-shaped deformity with a right-sided thoracolumbar curve measuring $38^{\circ}$ and a left-sided lumbar curve measuring $57^{\circ}$.

\section{Results}

\section{Patient Demographics}

The average age of our patients at the time of surgery was 14 years (range 10-20 years). In our cohort, 6 patients had a diagnosis of myelomeningocele, 12 patients had $\mathrm{CP}$, 1 patient had spinal muscle atrophy, and 2 had an unspecified neurodegenerative disorder (Table 1).

\section{Clinical and Operative Data}

All patients were assessed preoperatively with MRI,
CT, and upright 36-inch scoliosis radiographs. The average coronal Cobb angle of patients with neuromuscular spinal deformity measured $66^{\circ}$ (range $37-125^{\circ}$ ) before surgery (Fig. 3A). The average preoperative thoracic kyphosis and lumbar sagittal lordosis measured $43^{\circ}$ and $41^{\circ}$, respectively. Arthrodesis to the pelvis was performed using bilateral iliac screw fixation and posterolateral fusion with allograft/local autograft and rhBMP-2. All patients received either a 12-mg or 24-mg dose of rhBMP-2. Median blood loss was $976 \mathrm{ml}(300-2700 \mathrm{ml})$, and operative time was 7 hours 43 minutes (range 3 hours 59 minutes to 10 hours 23 minutes; Table 1).

In the immediate postoperative period, the average coronal Cobb angle was $40^{\circ}$, and the thoracic and lumbar angles were $32^{\circ}$ and $39^{\circ}$, respectively (Fig. 3B). Patients were followed up for an average of 17 months (range 2-54 months). No patient had significant progression of his or her deformity after surgery. The average coronal Cobb angle was maintained at $42^{\circ}$, and the thoracic and lumbar sagittal angles were maintained at $32^{\circ}$ and $37^{\circ}$, respectively, at most recent follow-up (Fig. 3C; Table 2).

We included HRQoL outcomes in Table 3 for a subset of our patients. These scores were unavailable for other patients. The mean PedsQL score for our cohort was 53.39 (range 15-85.87); this is below the mean of a pediatric patient population with chronic disease for both the parent proxy report and child self-report (67.4 and 68.3, respectively). The mean SRS-22 score for our patients was 4.31 (range 3.63-5.42). The mean ODI was 31\% (range $15 \%-53 \%$ ), corresponding to moderate disability. The mean SF-36 Physical Component Score (PCS) was 47.6 (range, 34.2-57.1), and the mean SF-36 Mental Component Score (MCS) was 46.7 (range 31.5-62.5). When compared with healthy population norms for the 18-24-year-old age group, the SF-36 PCS was below the 25th percentile (mean 54.11; 25th percentile, 52.11); the MCS was at the mean for the same age group (mean 46.40). Unfortunately, given the small sample size in which HRQoL outcomes were obtained, more meaningful comparisons to published norms could not be performed. Moreover, HRQoL outcomes tools such as he ODI and SF-36, which have been validated for the adult patient population, have not been similarly validated for pediatric counterparts.

\section{Complications}

There were 3 major complications in our series (Table 2): 1 death secondary to respiratory arrest 2 months after surgery (Case 6); proximal junctional kyphosis requiring a second surgery to extend fusion and spinal instrumentation (Case 4); and 2 neurological complications from passage of sublaminar bands resulting in transient dorsal column dysfunction and protracted paraparesis, respectively (Cases 1 and 21).

The two instances of spinal cord injury were directly related to sublaminar polyester band use $(2 / 21$, or $10 \%)$; there was loss of SSEPs and MEPs intraoperatively with sublaminar passage of the band near the apex of the deformity. We routinely use laminar hooks at the cephalad aspect of our spinal construct; therefore, the case of proximal junction kyphosis is likely not due to the use of sublaminar polyester bands at more distal vertebral levels. 


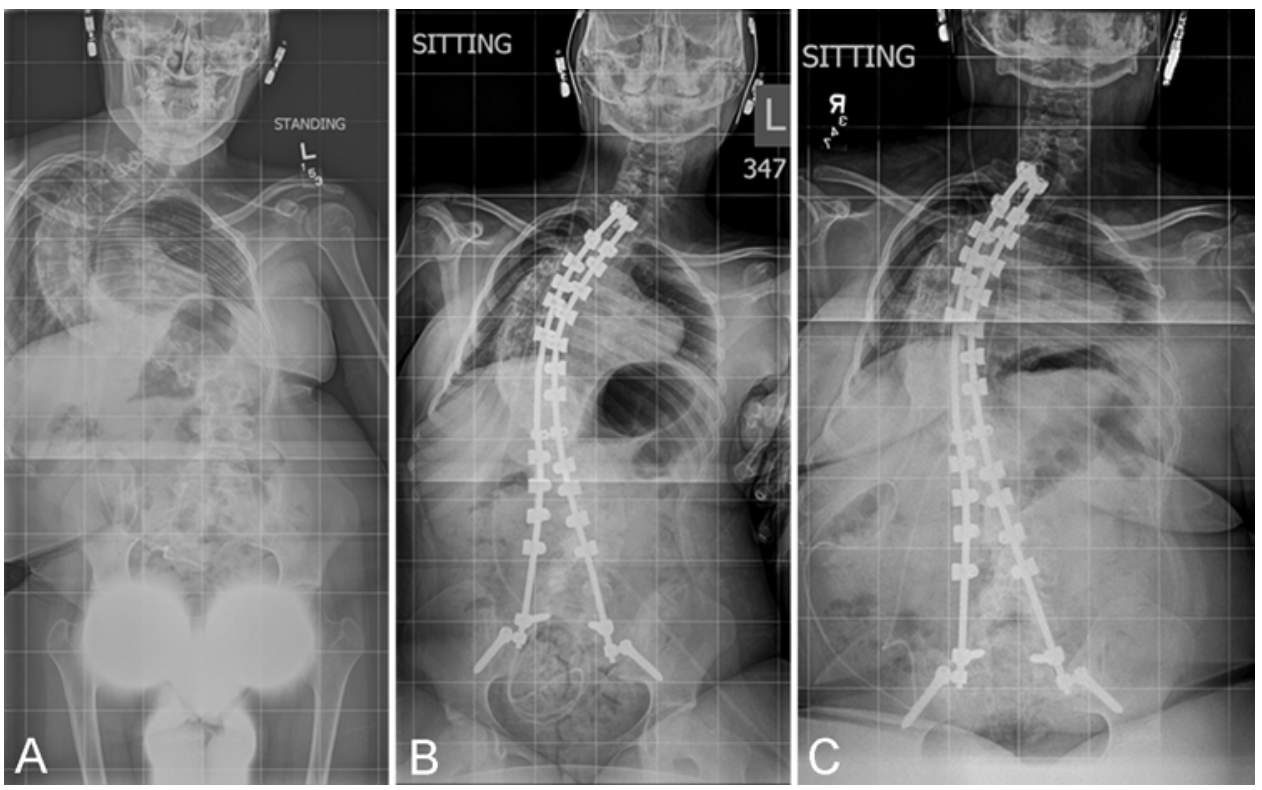

FIG. 3. Case 1. A: Preoperative, upright, AP 36 -inch scoliosis radiograph demonstrates a $101^{\circ}$ neuromuscular deformity. B: Immediate postoperative upright AP 36 -inch scoliosis radiograph exhibits an improvement to $62^{\circ}$. C: Postoperative upright $A P$ 36 -inch scoliosis radiograph for the same patient at the 50-month follow-up displays maintenance of the reduction attained immediately after surgery.

There were 3 minor complications that were deemed unrelated to the use of sublaminar polyester bands and included two cases (Cases 12 and 13) of wound drainage from sterile seroma occurring 3 to 4 weeks after surgery. We hypothesize that this drainage was associated with use of rhBMP-2. Finally, there was a single case of disengagement of a rod from the iliac screw (Case 11; Fig. 4). This is likely due to misfit of an "undersized" rod directly in the head of the iliac screw, rather than using an intervening lateral connector with a larger diameter and better purchase of the iliac screw head, as recommended by the manufacturer.

\section{Discussion}

\section{History of Spinal Instrumentation for Deformity}

The history of spinal implants began in Kansas in 1887 when Dr. B. F. Wilkins reduced and fixed a T12-L1 dislocation with silver wires that he passed around the pedicles. Stainless steel wires were developed in the late 1930s. The surgical treatment of spinal deformity was transformed in the 1960s when the Harrington rod instrumentation system was introduced. ${ }^{22}$ The next major advance in spinal instrumentation came in 1982, when Luque rods and sublaminar wires were introduced. The Luque instrumentation system provided segmental correction and fixation, allowing a more rigid construct that avoided mandatory postoperative external immobilization. ${ }^{15}$ The Cotrel-Dubousset instrumentation system, developed in Europe in 1978 and introduced in the US in 1984, has been described as a third-generation system that achieves 3D correction of spinal deformity. The hallmark of this instrumentation system was the segmental nature of the hook attachment that allowed multiple forces to be applied on the same rod to correct the spinal deformity. Since then, other third-gen- eration spinal systems combining the use of longitudinal members with different anchors in variable positions have been developed.

\section{Polyester Bands}

Recently, polyester bands with a locking mechanism to provide rod coupling (Universal Clamp) was developed as an alternative to traditional anchors, i.e., wires, hooks, and screws. The material properties of polyester are characterized by its high tensile strength, high resistance to stretch (wet or dry), and resistance to degradation..$^{21}$ Polyester is biocompatible without an excessive inflammatory reaction in surrounding tissue, including dura. Although we did not have a situation in which a sublaminar band needed to be removed in a delayed manner in our series, this biocompatible nature of Dacron should enable safe removal. Polyester has been in use for more than 20 years in spinal implants in Europe. ${ }^{16}$ Instrumentation costs associated with the Universal Clamp are similar to pedicle screw-rod methods.

Its woven fabric makes it gentle, and its flexibility make it an excellent alternative to implantation into the pediatric spine. ${ }^{26}$ The polyester bands and locking mechanism to the rod may be placed at multiple levels, similar to wires, hooks, and screws, to effect segmental control, reduction, and fusion. The polyester bands themselves are not radiographically visible, which reduces the metal artifact and enables the use of postoperative MRI (Fig. 5A and B). However, the radiolucent property of the bands also limits the evaluation of the instrumentation in the postoperative period (Fig. 5C and D).

The determination of the best construct to use for a specific patient is a multifactorial decision based on the skeletal maturity of the bone, complexity of the scoliosis, and surgeon preference. Studies have reported improved 


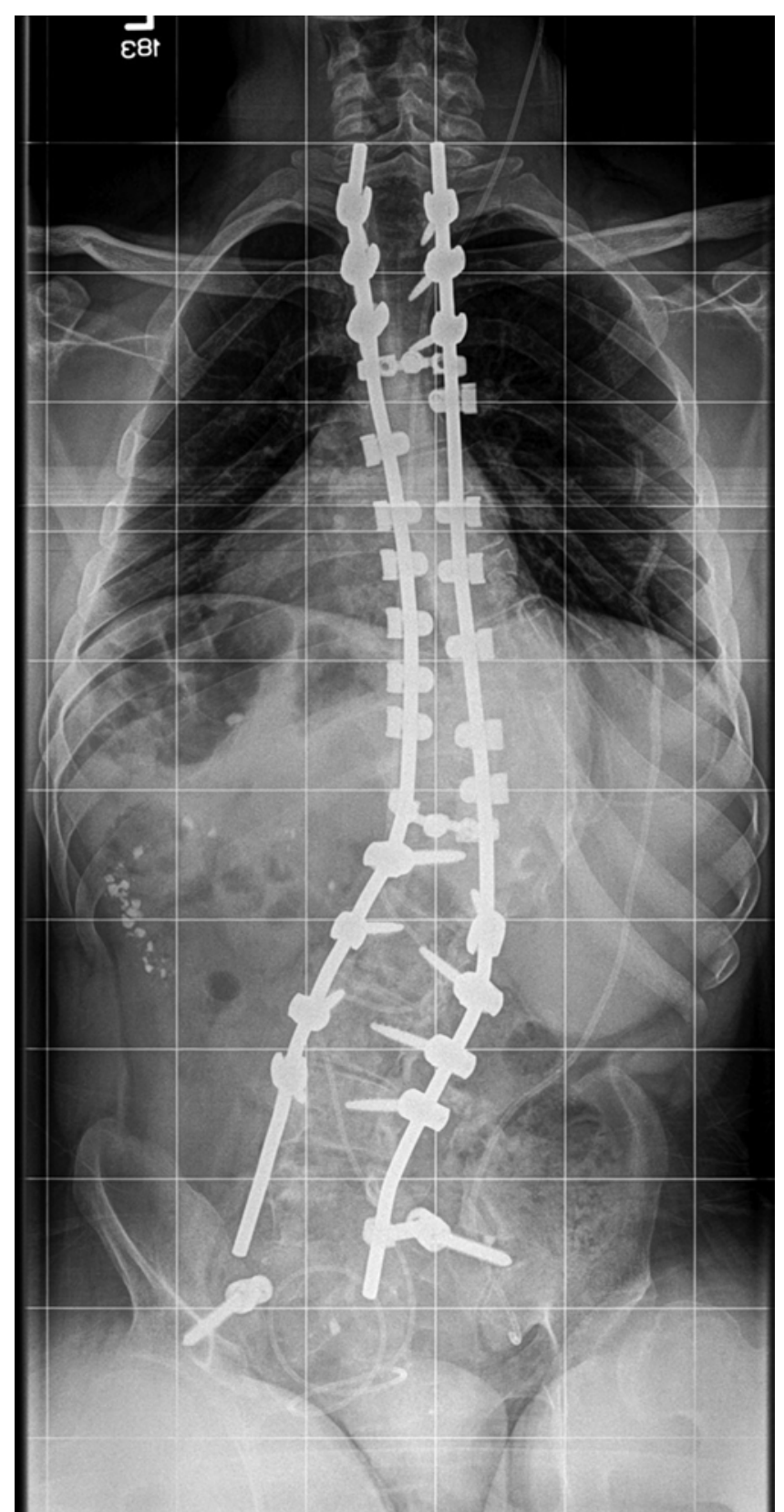

FIG. 4. Case 11. Postoperative upright AP 36-inch scoliosis radiograph reveals disengagement between the longitudinal rod and the corresponding iliac screw.

curve corrections with all screw and hybrid constructs as compared with all-hook constructs. ${ }^{19}$ However, studies comparing all-screw constructs with hybrid variants are limited. ${ }^{27}$ More biomechanical and clinical testing will be necessary to determine if a clinical superiority exists.

\section{Lessons Learned}

With the passage of any sublaminar instrumentation into the spinal canal, there is a risk of neurological injury. Theoretically, a polyester band, compared with a metal cable, should conform safely to the undersurface of the lamina, which may lead to a decrease in neurological injury. However, as in Cases 1 and 21, neurological in-
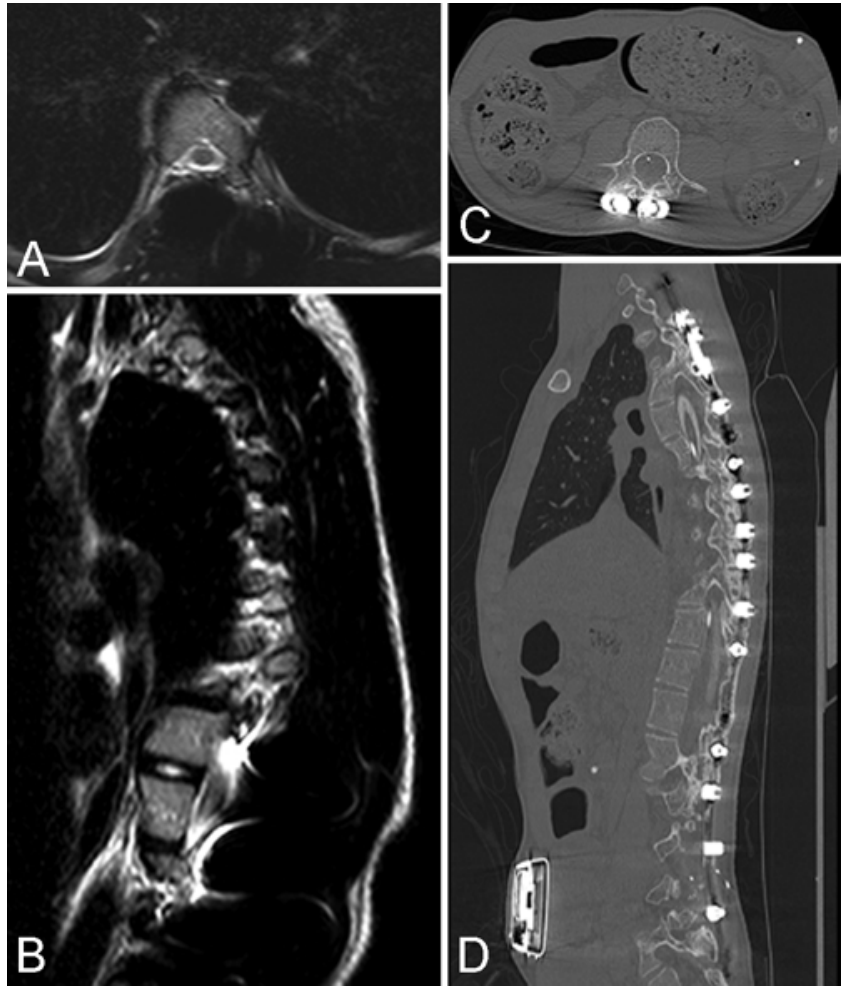

FIG. 5. Immediate postoperative T2-weighted axial (A) and sagittal (B) MR images of Case 21 show metal artifact that obscures examination of the neural elements within the spinal canal. Axial (C) and sagittal (D) CT scans of the spine of Case 15 at 3 months after surgery showing bone fusion mass maturing along with fusion of the facet joints. There is a streak artifact from the titanium clamps, but the bands themselves are radiolucent.

jury remains a risk with passage of sublaminar polyester bands.

Like sublaminar wires, sublaminar polyester bands can directly traumatize the spinal cord.,5,6,9,11,12,14,20 Because the metal tip is not visible during the sublaminar passage of the polyester band, the surgeon is unable to appreciate the depth of tip penetration into the spinal canal. Important points to consider when using this technique include the following: 1) the radius of curvature of the malleable metal tip should be at least equal to the length of the lamina; 2) the bend of the tip should not be greater than $45^{\circ}$; 3) lateral passage of sublaminar polyester bands should be avoided; 4) removal of additional bony lamina is not necessary because it does not significantly decrease the depth of band penetration but potentially weakens the lamina and increases the risk of instrumentation failure; ${ }^{1}$ 5 ) removal of the spinous process is recommended before direct midline passage of the sublaminar band; and 6) one should maintain tension on the band throughout passage by using a push-pull technique to prevent bowing of the band into the spinal canal.

A large study ${ }^{20}$ of 19,360 pediatric scoliosis cases compared complication rates associated with surgical treatment for the major subtypes of pediatric scoliosis. This report provides separate complication rates for neuromuscular, congenital, and idiopathic scoliosis and demonstrates significantly different rates of complications among these 
subtypes. This report also documents the increased complication rates associated with revision surgery and with procedures including corrective osteotomies. In addition, this modern series enables demonstration of the significantly lower rates of neurological injury associated with pedicle screw-only constructs compared with reconstructions based on anterior screws or posterior wires.

Surgery for neuromuscular scoliosis had the highest overall complication rate (17.9\%) and the highest mortality rate $(0.34 \%)$ in the present series. The overall complication rate in the present series is within the range of these prior studies $\left(0 \%{ }^{20}-33 \%^{19}\right)$. Although no cases of mortality are reported in most prior series, ${ }^{4,17-19,23-25}$ Barsdorf et al. reported a mortality rate of $1.6 \%$ ( 7 of 437 cases) following surgery for neuromuscular scoliosis, based on the National Inpatient Sample between 1997 and 2003. ${ }^{2}$

In an effort to assess for potential differences in the rates of new neurological deficit associated with type of instrumentation used, we assessed these rates in cases that used only a single type of instrumentation, specifically pedicle screws, anterior screws, hooks, or wires. Pedicle screw-only and hook-only constructs had comparable overall rates of new neurological deficits. In contrast, anterior screw-only and wire-only constructs had greater than 2 -fold higher rates of new neurological deficits. It is possible that the higher rate of deficits associated with wireonly constructs may result from direct trauma as wires are passed sublaminarly, because the majority of these were spinal cord deficits.

\section{Limitations of the Study}

The purpose of our study was not specifically to determine fusion rates associated with this technique. Much longer-term follow-up would be mandatory as the fusion process typically takes 6-12 months after surgery. ${ }^{13}$ Our primary objective was to determine the feasibility and safety of using sublaminar polyester bands in posterior instrumented fusions for neuromuscular scoliosis.

\section{Conclusions}

Posterior instrumented spinal fusions in children and transitional adults with small or abnormal anatomy from congenital or acquired deformities represent technically challenging cases. Freehand, or even fluoroscopically guided, placement of pedicle screws in these patients is difficult even in the best of hands. Hooks and metal sublaminar wires are technically straightforward, but they have their drawbacks, including high bone-implant interface stress and risk of bone fracture in the weak or skeletally immature spine. We report the first use of polyester bands in spine surgery in children and transitional adults with neuromuscular scoliosis in the US as an effective alternative to wires, hooks, and screws in 21 patients with significant spinal deformities. However, the association with neurological adverse events with this sublaminar technique is high (10\%). More follow-up studies are needed to determine the long-term effects and outcomes in maintenance of deformity correction of posterior spinal fusions with hybrid hook-screw-polyester band constructs in pediatric and adult spinal deformities. Moreover, further refinement in the use of polyester bands, such as passage around the transverse process rather than the lamina, is needed to improve the safety profile of this technique.

\section{References}

1. Aydingoz O, Bilsel N, Botanlioglu H, Bozdag E, Sunbuloglu $\mathrm{E}$, Kesmezacar H: Effect of decortication on laminar strength during sublaminar wiring: an experimental study. J Spinal Disord Tech 17:498-504, 2004

2. Barsdorf AI, Sproule DM, Kaufmann P: Scoliosis surgery in children with neuromuscular disease: findings from the US National Inpatient Sample, 1997 to 2003. Arch Neurol 67:231-235, 2010

3. Ben-David B: Spinal cord monitoring. Orthop Clin North Am 19:427-448, 1988

4. Benson ER, Thomson JD, Smith BG, Banta JV: Results and morbidity in a consecutive series of patients undergoing spinal fusion for neuromuscular scoliosis. Spine (Phila Pa 1976) 23:2308-2318, 1998

5. Burke SD, Matiko J: Segmental spinal instrumentation in neuromuscular spinal deformity. Orthop Trans 7:25-26, 1983

6. Carlioz H, Ouaknine M: [Neurologic complications of surgery of the spine in children.] Chirurgie 120:26-30, 19941995 (Fr)

7. Cheng I, Kim Y, Gupta MC, Bridwell KH, Hurford RK, Lee SS, et al: Apical sublaminar wires versus pedicle screwswhich provides better results for surgical correction of adolescent idiopathic scoliosis? Spine (Phila Pa 1976) 30:21042112, 2005

8. Cordista A, Conrad B, Horodyski M, Walters S, Rechtine G: Biomechanical evaluation of pedicle screws versus pedicle and laminar hooks in the thoracic spine. Spine J 6:444-449, 2006

9. Girardi FP, Boachie-Adjei O, Rawlins BA: Safety of sublaminar wires with Isola instrumentation for the treatment of idiopathic scoliosis. Spine (Phila Pa 1976) 25:691-695, 2000

10. Gressot LVPA, Patel AJ, Hwang SW, Fulkerson DH, Jea A: Iliac screw placement in neuromuscular scoliosis using anatomical landmarks and uniplanar anteroposterior fluoroscopic imaging with postoperative CT confirmation. J Neurosurg Pediatr 13:54-61, 2014

11. Herring JA, Wenger DR: Segmental spinal instrumentation: a preliminary report of 40 consecutive cases. Spine (Phila Pa 1976) 7:285-298, 1982

12. Johnston CE II, Happel LT Jr, Norris R, Burke SW, King AG, Roberts JM: Delayed paraplegia complicating sublaminar segmental spinal instrumentation. J Bone Joint Surg Am 68:556-563, 1986

13. Kalfas IH: Principles of bone healing. Neurosurg Focus 10(4):E1, 2001

14. Lonstein JE, Winter RB, Moe JH, Bradford DS, Chou SN, Pinto WC: Neurologic deficits secondary to spinal deformity. A review of the literature and report of 43 cases. Spine (Phila Pa 1976) 5:331-355, 1980

15. Luque ER: Segmental spinal instrumentation for correction of scoliosis. Clin Orthop Relat Res (163):192-198, 1982

16. Mazda K, Ilharreborde B, Even J, Lefevre Y, Fitoussi F, Penneçot GF: Efficacy and safety of posteromedial translation for correction of thoracic curves in adolescent idiopathic scoliosis using a new connection to the spine: the Universal Clamp. Eur Spine J 18:158-169, 2009

17. Modi HN, Hong JY, Mehta SS, Srinivasalu S, Suh SW, Yi JW, et al: Surgical correction and fusion using posterior-only pedicle screw construct for neuropathic scoliosis in patients with cerebral palsy: a three-year follow-up study. Spine (Phila Pa 1976) 34:1167-1175, 2009

18. Modi HN, Suh SW, Hong JY, Cho JW, Park JH, Yang JH: 
Treatment and complications in flaccid neuromuscular scoliosis (Duchenne muscular dystrophy and spinal muscular atrophy) with posterior-only pedicle screw instrumentation. Eur Spine J 19:384-393, 2010

19. Mohamad F, Parent S, Pawelek J, Marks M, Bastrom T, Faro F, et al: Perioperative complications after surgical correction in neuromuscular scoliosis. J Pediatr Orthop 27:392-397, 2007

20. Reames DL, Smith JS, Fu KM, Polly DW Jr, Ames CP, Berven SH, et al: Complications in the surgical treatment of 19,360 cases of pediatric scoliosis: a review of the Scoliosis Research Society Morbidity and Mortality database. Spine (Phila Pa 1976) 36:1484-1491, 2011

21. Seitz H, Marlovits S, Schwendenwein I, Müller E, Vécsei V: Biocompatibility of polyethylene terephthalate (Trevira hochfest) augmentation device in repair of the anterior cruciate ligament. Biomaterials 19:189-196, 1998

22. Singh H, Rahimi SY, Yeh DJ, Floyd D: History of posterior thoracic instrumentation. Neurosurg Focus 16(1):E11, 2004

23. Suh SW, Modi HN, Yang J, Song HR, Jang KM: Posterior multilevel vertebral osteotomy for correction of severe and rigid neuromuscular scoliosis: a preliminary study. Spine (Phila Pa 1976) 34:1315-1320, 2009

24. Teli M, Elsebaie H, Biant L, Noordeen H: Neuromuscular scoliosis treated by segmental third-generation instrumented spinal fusion. J Spinal Disord Tech 18:430-438, 2005

25. Thacker M, Hui JH, Wong HK, Chatterjee A, Lee EH: Spinal fusion and instrumentation for paediatric neuromuscular scoliosis: retrospective review. J Orthop Surg (Hong Kong) 10:144-151, 2002

26. Viswanathan A, Johnson KK, Whitehead WE, Curry DJ, Luerssen TG, Jea A: Hybrid spinal constructs using sublaminar polyester bands in posterior instrumented fusions in children: a series of 5 cases. Neurosurg 66:862-867, 2010

27. Vora V, Crawford A, Babekhir N, Boachie-Adjei O, Lenke L, Peskin M, et al: A pedicle screw construct gives an enhanced posterior correction of adolescent idiopathic scoliosis when compared with other constructs: myth or reality. Spine (Phila Pa 1976) 32:1869-1874, 2007

\section{Author Contributions}

Conception and design: Jea. Acquisition of data: Jea, Brayton. Analysis and interpretation of data: Jea, Vener, Briceño. Drafting the article: Jea, Desai. Critically revising the article: Jea, Desai, Sayama. Reviewed submitted version of manuscript: Jea, Desai, Sayama, Vener, Brayton, Briceño. Approved the final version of the manuscript on behalf of all authors: Jea. Study supervision: Luerssen.

\section{Correspondence}

Andrew Jea, Neuro-Spine Program, Texas Children's Hospital, CCC 1230.01, 12th Fl., Houston, TX 77030. email: ahjea@ texaschildrens.org. 